\title{
Apresentação
}

\section{Estudos de descrição e análise da língua espanhola}

A língua espanhola é o segundo idioma no mundo, com mais de 570 milhões de falantes, entre nativos, não nativos e aprendizes, conforme o Anuário "El español en el mundo 2018". ${ }^{1}$ A importância do idioma no cenário mundial é notória, já que é a língua românica mais falada, e disputa com o francês e o mandarim o posto entre os idiomas mais estudados como segunda língua, conforme dados do Anuário de 2018. Além de ser a terceira língua empregada nas publicações de um modo geral.

No Brasil, em razão do objetivo de integração com os demais países da América Latina, o que coincide com a criação do Mercosur e com investimentos espanhóis entre 1998 e 2000 (CORRAL SÁNCHEZ-CABEZUDO, 2007), a língua espanhola passou a ser objeto de interesse para estudantes e para investigadores, de tal forma que, até 2018, o Brasil era o segundo país no ranking de estudantes de espanhol como segunda língua no mundo. ${ }^{2}$

O aumento no número de hispanofalantes faz crescer também o número de interessados em descrever essa língua no âmbito das investigações linguísticas, de modo a explicar seu emprego e seu funcionamento nas mais diversas situações comunicativas.

Com o intuito de agrupar trabalhos que tenham como alvo de investigação o idioma espanhol, este número temático reúne contribuições que abordam a descrição e a análise da língua espanhola sob variados enfoques teóricos. Os estudos aqui

\footnotetext{
${ }^{1}$ Disponível em: https://cvc.cervantes.es/lengua/espanol lengua viva/pdf/espanol lengua viva 2018.pdf. Acesso em: 6 jan. 2020.

${ }^{2}$ Cf. Anuário 2018, p. 11.
} 
reunidos analisam algumas variedades do espanhol falado ou escrito, sincronicamente ou diacronicamente, contemplando a língua como objeto de estudo e de reflexão em diferentes níveis de análise linguística, tanto isoladamente como em comparação com outras línguas.

Os 13 trabalhos publicados neste número relacionam-se a diferentes áreas da Linguística, como (i) aquisição do espanhol como língua materna/estrangeira com foco em descrição linguística; (ii) aspectos fonéticos e fonológicos do idioma; (iii) aspectos morfossintáticos, semânticos e pragmáticos; (iv); variação e mudança linguística; (v) análise de aspectos funcionais nas variedades do espanhol; (vi) análise de aspectos formais nas variedades do espanhol; (vii) lexicografia, lexicologia e terminografia; (viii) estudos da tradução entre o espanhol e as outra(s) língua(s), e (ix) estudos linguísticos de natureza comparativa entre o espanhol e as outra(s) língua(s).

A variedade de áreas contempladas associa-se também a uma diversidade de materiais analisados. Assim, as descrições realizadas baseiam-se em gramáticas e em manuais de língua espanhola, em produções orais e escritas de nativos e de não nativos, em dicionários, em corpus que trazem amostras de língua falada (como o PRESEEA, o Macrocorpus e o C-Oral), e de língua escrita (como o Crea), e em materiais midiáticos, como quadrinhos e uma série televisiva.

No artigo intitulado Uma breve revisão da gramaticografia hispânica, os autores Leandro Silveira de Araujo e Fernanda Silva Freitas buscam identificar quais são e como foram compostas as gramáticas da língua espanhola ao longo da história. Para tanto, levantam dados textuais (como a categorização da língua) e extratextuais (como origem, autoria, data, propósito e público alvo) em 108 registros diferentes de manuais e de gramáticas da língua espanhola. A pesquisa, de cunho qualitativo exploratório, compreende gramáticas voltadas à descrição e ao ensino da língua espanhola com em busca nos sites de acervo de universidades brasileiras e estrangeiras. Os dados levantados são agrupados por origem geográfica, por tempo, por autor e por 
finalidade da obra. Os resultados contribuem para a compreensão de como se deram as mudanças de visão sobre a língua espanhola, bem como os fatores que suscitam tais mudanças.

No artigo intitulado Descripción de la abertura y del alzamiento de los sonidos vocálicos [e] y [o] en la pronunciación de estudiantes potiguares y cearenses de Letras español, a autora Maria Solange de Farias analisa os erros relacionados com a abertura e com o alçamento dos fonemas [e] e [o] na interlíngua de graduandos potiguares e cearenses, em processo de aprendizagem de espanhol como língua estrangeira. $\mathrm{Na}$ análise, a pesquisadora constata que os erros presentes na interlíngua oral desses estudantes são a abertura de [e] e de [o] em 59\% dos casos, e o alçamento de [e] e de [o] em $41 \%$ dos casos. Tais erros se fossilizaram, uma vez que estão presentes em todos os níveis de aprendizagem de modo que, enquanto a abertura de [e] e de [o] não dificulta a comunicação, o alçamento de [e] e de [o] impede a comunicação porque pode gerar diferenças de significado. A autora argumenta ainda que a razão para a manutenção de tais erros em todos os níveis pode estar relacionada, de um modo geral, à pouca formação para aprender os elementos segmentais.

O artigo intitulado $A$ variação entre possessivos simples e perifrásticos de $3^{\underline{a}}$ pessoa no espanhol, de Vanessa de Azevedo Baeta Alves Pereira e de Leonardo Lennertz Marcotulio, traz a análise do fenômeno de variação entre possessivos simples e perifrásticos de $3^{\underline{a}}$ pessoa no espanhol, com base em amostras de fala disponíveis no corpus Macrocorpus e em uma perspectiva teórico-metodológica sociolinguística de base laboviana (WEINREICH; LABOV; HERZOG, 1968; LABOV, 1972). Com base em fatores internos e externos como possíveis condicionantes da variação entre essas formas, os dados são submetidos a um tratamento estatístico, com o qual os autores constatam que as formas perifrásticas de $3^{\underline{a}}$ pessoa no espanhol servem ao paradigma possessivo, desfazendo a ambiguidade referencial inerente às formas simples, de modo a tornar mais clara a relação de posse em contextos de múltiplos referentes. A 
descrição traz uma reflexão acerca da expressão da posse em espanhol, de modo a contribuir para possíveis desdobramentos no que se refere ao ensino dessa língua.

No artigo intitulado Tipología con fines pedagógicos de los verbos locativos del español, de Roana Rodrigues examina o funcionamento sintático-semântico das construções locativas da língua espanhola, nas quais o elemento locativo não é um simples complemento adverbial, mas faz parte da valência do verbo (argumento locativo). Com base no Léxico-Gramática de Verbos Locativos do Espanhol (LGLE), que agrupa 318 verbos locativos, a autora os redistribui em duas grandes classes formais, quais sejam: (i) verbos locativos preposicionais e (ii) verbos locativos transitivos diretos, de modo a organizá-los em verbos prototípicos, que se referem aos que têm maior possibilidade e maior liberdade de seleção do argumento locativo; restritivos, cujas construções permitem a omissão de um argumento locativo e que permitem a seleção de nome toponímico na posição de argumento locativo; $e$ denominais, que apresentam construções de lugar, de instrumentos e de maneiraposição. Para além da análise empreendida, a pesquisa contribui para a sistematização dos dados com propósitos pedagógicos para o ensino de espanhol como língua materna e/ou língua estrangeira.

No artigo intitulado Telicidade e determinantes plurais indefinidos no espanhol da Espanha, os autores Jean Carlos da Silva Gomes e Adriana Leitão Martins partem da noção aspectual semântica de telicidade para investigar a compatibilidade da partícula conhecida como se télico com verbos cujos complementos são introduzidos por determinantes plurais indefinidos. Inicialmente, os autores mostram como a noção aspectual de telicidade pode ser realizada no espanhol e buscam avaliar a hipótese de que o se télico não se combina com complementos verbais introduzidos por determinantes plurais no espanhol da Espanha. Para tanto, analisam amostras de espanhol falado extraídos do Projeto PRESEEA e do corpus C-Oral, selecionando todas as ocorrências de complementos verbais introduzidos pelos determinantes plurais 
indefinidos unos(as), algunos(as), muchos(as), varios(as) e aplicando testes de julgamento de gramaticalidade a falantes nativos. A análise dos traços semânticos aspectuais de estatividade e de duratividade presentes nos verbos selecionados permite verificar que a combinação hipotetizada inicialmente é possível e aponta, ainda, para novos direcionamentos à pesquisa.

No artigo intitulado Traços de iteratividade e suas realizações em línguas próximas, as autoras Maria Mercedes Riveiro Quintans Sebold e Anne Katheryne Estebe Maggessy discutem a noção aspectual da iteratividade. Mais especificamente, confrontam diferentes estudos sobre a iteratividade e pontuam os achados de tais pesquisas. Desse modo, averiguam a possibilidade de se entender a iteratividade como uma noção aspectual que se constrói alicerçada em traços sobrepostos próximos de outros aspectos. Nessa direção, examinam a realização morfológica de tal aspecto em duas línguas tipologicamente próximas: o português do Brasil e o espanhol, destacando a questão da composicionalidade do aspecto. As autoras propõem que (i) o contexto genericidade parece favorecer a iteratividade nas duas variedades analisadas; (ii) o aspecto iterativo é a combinação de elementos da sentença; (iii) as perífrases de gerúndio com valor iterativo na variedade do Rio de Janeiro se mostra produtiva com argumentos plurais e com expressões adverbiais de quantidade e de intensidade, e (iv) a perífrase aspectual durativa se mostra mais produtiva na variedade do espanhol da cidade do México.

O Funcionalismo Linguístico, abordagem teórica que investiga o emprego da língua em contextos reais, é a base teórica adotada por três artigos deste número temático. Tais artigos inserem-se especificamente dentro da Gramática Funcional de linha holandesa, voltados especificamente para a aplicação do modelo teórico da Gramática Discursivo-Funcional (GDF), proposta por Hengeveld e Mackenzie (2008).

No artigo intitulado As modalidades deôntica e volitiva e a implicatura de futuridade em tebeos de língua espanhola, os autores Maria de Fátima Sousa Lopes e André Silva 
Oliveira abordam a questão da modalidade e a relação entre modalidade e futuridade fundamentados na análise de tebeos publicados de forma online de Mafalda e Gaturro, dois personagens conhecidos do mundo hispânico. Com base na classificação de modalidade proposta por Hengeveld (2004), os autores descrevem, qualitativamente, as ocorrências de modalidade deôntica e volitiva e sua incidência semânticoargumentativa no que se refere à implicatura de futuridade. Além dos valores modais, o trabalho investiga a controlabilidade e a dinamicidade do Estado de Coisas, a incidência da negação sobre o elemento modalizador e os traços semânticos do sujeito. Os autores verificam que as ocorrências de elementos modais deônticos e volitivos estão estreitamente relacionados com a futuridade, por expressarem uma obrigação ou um desejo que deverá se concretizar no futuro próximo ou distante.

No artigo intitulado La partícula incluso en construcciones introducidas por incluso si bajo la perspectiva discursivo-funcional, as autoras Bárbara Ribeiro Fante e Talita Storti Garcia verificam, em dados do espanhol peninsular extraídos do banco de dados do CREA (Corpus de Referencia del Español Actual) se a partícula incluso é uma marca de ênfase, o que permitiria tratá-la como independente da conjunção condicional si. Com base no arcabouço teórico da Gramática Discursivo-Funcional e nos seus quatro níveis de análise (interpessoal, representacional, morfossintático e fonológico) as autoras propõem testes a fim de avaliar as unidades que a construção pode tomar por escopo, partindo da hipótese de que a construção atua nos níveis mais altos do modelo, a saber, o interpessoal e o representacional. Por meio da análise das ocorrências, as autoras verificam que a construção incluso si pode atuar tanto no Nível Representacional, de natureza semântica, como no Nível Interpessoal, de natureza pragmática, o que revela dois tipos diferentes da construção, sendo um deles não previsto nas obras de referência do espanhol.

A GDF também é o modelo teórico adotado no artigo Multifuncionalidade de aun/aún e todavia no espanhol peninsular, de autoria de Michel Gustavo Fontes. Com o 
apoio de amostras do espanhol peninsular falado extraídas do Projeto PRESEEA (Proyecto para el Estudio Sociolingüístico del Español de España y de América), mais especificamente das cidades espanholas de Alcalá de Henares, de Madri e de Valência, os autores buscam mapear propriedades funcionais e formais que permitem distinguir os itens analisados no interior do sistema gramatical da língua espanhola. Para proceder à análise da multifuncionalidade dos itens, o autor parte de dois aspectos: as diferentes relações de escopo presentes em cada um dos usos identificados, considerando os níveis de formulação da Gramática Discursivo-Funcional (interpessoal e representacional) e os diferentes estatutos categoriais que os itens assumem, o que pode evidenciar um estatuto lexical ou gramatical. A análise empreendida revela quatro usos distintos de aún/aun e de todavía no espanhol peninsular, que se manifestam em diferentes camadas do modelo teórico.

No artigo intitulado Análise do discurso de dois dicionários bilíngue PortuguêsEspanhol à luz da Linguística Sistêmico Funcional e da Análise Crítica do Discurso, Ivan Pereira de Souza aplica o modelo teórico da Linguística Sistêmico-Funcional aliado à Análise Crítica do Discurso para analisar o discurso de dois dicionários bilíngues português-espanhol/espanhol-português usados em escolas de ensino fundamental e médio de uma região do norte do Brasil: Michaelis minidicionário Espanholportuguês/português-espanhol, da editora Melhoramentos, e Dicionário Santillana para estudantes espanhol-português/português-espanhol, da editora Moderna, que foram tratados como dicionários bilíngues pedagógicos. A análise baseia-se nas três variáveis do discurso (campo do discurso, relação entre os participantes do discurso e modo) e os resultados permitem avaliar a pertinência dos modelos teóricos adotados, além de oferecer uma visão também discursiva dos dicionários usados para o ensino de língua estrangeira.

A tradução audiovisual (TAV), segundo Díaz Cintas (2001), é uma área que, nas últimas décadas, vive uma verdadeira revolução em razão da crescente demanda de 
produtos audiovisuais produzidos em todo o mundo. Nesse contexto, com o objetivo de contribuir com a tradução e com a legendagem de produtos audiovisuais da língua espanhola para o português do Brasil, no artigo intitulado O marcador 'por cierto' e suas versões em português: uma análise das legendas da série espanhola "El Ministerio del Tiempo", os autores Daniel Mazzaro e Mariana Ferreira Ruas analisam as traduções do marcador discursivo por cierto nas legendas da série espanhola "El Ministerio del Tiempo" para o português do Brasil. Os autores concluem que, embora mais da metade das traduções tenham sido adequadas ao contexto comunicativo e ao gênero discursivo (incluindo o seu apagamento), há relevantes casos em que a tradução guia a outras inferências, por empregar marcadores em língua portuguesa que se aproximam mais da estrutura lexical do marcador por cierto do que de seus significados de processamento.

No artigo intitulado Interferências linguísticas em produções textuais de venezuelanos aprendizes de português como língua estrangeira, o autor Fabricio Paiva Mota examina as interferências linguísticas presentes em produções textuais de venezuelanos aprendizes de português como língua estrangeira, considerando três tipos de interferência: (i) a ortográfica (acentuação e grafia); (ii) a lexical (empréstimo e tradução direta); e a (iii) gramatical (casos que atingem a estrutura gramatical do português escrito pelos alunos). Os resultados da pesquisa apontam para uma interferência linguística do tipo ortográfica, em que o aluno, no processo de aprendizagem, omite o acento gráfico em palavras da língua portuguesa e também confunde os grafemas. No que se refere à interferência gramatical, o trabalho mostra um equilíbrio entre os fatores sintáticos, como concordância, e morfofonológicos. Em relação à interferência lexical, o autor verifica que o empréstimo é o meio mais usado pelos aprendizes. Tais resultados podem subsidiar estudos comparativos e a formação de professores. 
No artigo intitulado Interlíngua e interferência da língua materna em textos de estudantes de espanhol de uma escola em Porto Velho/RO, as autoras Ariane Rosas da Silva e Nádia Nelziza Lovera de Florentino analisam as transferências da língua materna em textos de estudantes de espanhol, baseadas em dez produções textuais, por meio do método de análise contrastiva, como tentativa de explicar a ocorrência dos erros de transferências e de interlíngua encontrados. Com base nos dados obtidos, as autoras estabelecem os erros mais frequentes, destacando-se (i) o uso inadequado do neutro lo, em $40 \%$ dos casos, equivocadamente empregado pelos estudantes diante de substantivos masculinos; (ii) a dificuldade de conjugação do verbo venir; (iii) a ortografia incorreta da conjunção aditiva $y$.

A distinção entre linguística teórica e aplicada está marcada pela fronteira existente entre ciência pura e ciência aplicada. Tal distinção tem sido operativa no campo das ciências naturais, mas não tanto nas ciências sociais e humanas, como nos explica Santos Gargallo (2010). Essa constatação pode ser verificada pela imbricada relação que se estabeleceu na construção de artigos desta edição especial, que versam sobre a descrição de aspectos relacionados à (inter)língua e que procuram trazer reflexões para o ensino de espanhol.

Desejamos que a leitura desta edição contribua para a compreensão de fenômenos relacionados à descrição da língua espanhola, seja como língua materna ou como língua estrangeira, e sirvam de inspiração para outras pesquisas nessa área. 


\section{Referências}

ANUÁRIO “EL ESPAÑOL EN EL MUNDO 2018”. Instituto Cervantes. Disponível em: encurtador.com.br/xAJQZ. Acesso: 6 jan. 2020.

CORRAL SÁNCHEZ-CABEZUDO, F. El español en Brasil. In: Instituto Cervantes. Enciclopedia del español en el mundo 2007. Disponível em:

https:/cvc.cervantes.es/lengua/anuario/anuario_06-07/pdf/paises_37.pdf. Acesso: 25 mar. 2020.

DÍAZ CINTAS, J. La traducción audiovisual: El subtitulado. Salamanca, Ediciones Almar, 2001.

HENGEVELD, K. Illocution, mood, and modality. In: BOOIJ, G.; LEHMANN, C.; MUGDAN, J. (eds.) Morphology: a handbook on inflection and word formation. v. 2. Berlin: Mouton de Gruyterp. 1190-1201, 2004.

HENGEVELD, K.; MACKENZIE, J. L. Functional Discourse Grammar: a typologically-based theory of language structure. Oxford: Oxford Linguistics, 2008.

LABOV, W. Sociolinguistic Patterns. Philadelphia: University of Pensylvania Press, 1972.

SANTOS GARGALLO, I. Lingüística aplicada a la enseñanza-aprendizaje del español como lengua extranjera. Madrid: Arcos Libros, 2010.

WEINREICH, U., LABOV, W., HERZOG, M. I. Empirical foundations for a theory of language change. In: LEHMANN, W.; MALKIEL, Y. Directions for historical linguistics. University of Texas Press, 1968. 